\title{
SER OU NÃO SER, EIS A QUESTÃO: um estudo sobre a Sociedade da informação no Brasil
}

\author{
TO BE OR NOT TO BE, THAT IS THE QUESTION: \\ a study on the Information Society in Brazil
}

Humberta Karinne da Conceição Santos Silva ${ }^{1}$

Anna Karenina Chaves Delgado

\begin{abstract}
RESUMO
0 pós-moderno, além de apresentar-se como sinônimo de descontinuidade, seja em relação a ideias, paradigmas também passa a imagem de algo que suplanta fronteiras políticas, econômicas, filosóficas, culturais e sociais, em relação ao pensamento anterior. Esse novo paradigma tem na aquisição e distribuição de conhecimento, em conjunto com as TIC's, uma maior integração no desenvolvimento social dos cidadãos do novo milênio - quando incluídos digitalmente -, constituindo, assim, a verdadeira 'sociedade da informação'. 0 presente artigo explora a hipótese: a sociedade da informação que atua de modo global está de fato modificando radicalmente a vida em sociedade ou apenas reforça ou confirma o sistema vigente, principalmente, no Brasil? Por meio de uma pesquisa qualitativa, de caráter bibliográfico ampliou-se o olhar para os entornos, analisou-se atentamente os discursos sobre produção cientifica, diferenciação entre informação e conhecimento, sua utilidade e funcionalidade. A relevância para o campo da administração é a de analisar os diferentes significados da realidade, baseada nas discussões sobre como vive-se o novo paradigma, no tocante a produção do conhecimento e sua influência no modo de ser e estar na pós-modernidade e os seus reflexos para a realidade social, sobretudo, no Brasil. Conclui-se que o paradigma científico da pós modernidade é uma utopia em qualquer sociedade. Uma vez que 0 acesso ao conhecimento, e seus efeitos na atividade humana, individual ou coletiva, e a flexibilidade, que permite modificação e reorganização social, não será acessada pelas comunidades menos privilegiadas economicamente, o que resulta em uma expansão das desigualdades em todas as esferas.
\end{abstract}

Palavras-chaves: Pós-modernidade. Sociedade do conhecimento. Sociedade da informação.

\section{ABSTRACT}

The postmodern not only presents itself as a synonym of discontinuity, in relation to ideas, paradigms, but also, passes the idea of something that supplants political, economic, philosophical, cultural and social frontiers, over the previous thought. This new paradigm has in the acquisition and distribution of knowledge in conjunction with information and communication technologies (ICTs) a greater integration and social development of citizens of the new millennium - when included digitally -, this would constitute a true 'knowledge society'. This article explores the hypothesis: does the information society, which acts globally, change life in society radically or only reinforces or confirms the current system, especially, in Brazil? Through a qualitative research, of a bibliographical character, it was extended the look to the surroundings, the discourses on scientific production, the differentiation between information and knowledge, its usefulness and functionality. The relevance to the field of administration is to analyze the different meanings of reality, based on the discussions about how the new paradigm is lived, regarding the production of knowledge and its influence on the way of being and being in postmodernity and the its reflections on social reality, especially in Brazil. We conclude that the scientific paradigm of post modernity is a utopia in any society. Since access to knowledge, and its effects on human activity, individual or collective, and flexibility, which allows social modification and reorganization, will not be accessed by economically less privileged communities, resulting in an expansion of inequalities in all spheres.

Keywords: Postmodernity. Knowledge society. Information society.

Artigo recebido em 31/01/2019 e aceito para publicação em 27/05/2019.

1 Mestre em Administração pela Universidade Federal de Pernambuco, Brasil. Professora do Estado da Paraíba, Brasil. E-mail: humbertakarinne87@gmail.com.

2 Doutora em Administração pela Universidade Federal de Pernambuco, Brasil. Professora do Instituto Federal de Pernambuco , Brasil. E-mail: anna.chaves@cabo.ifpe.edu.br. 


\section{INTRODUÇÃ̃O}

Vive-se um momento histórico de mudança paradigmática. Da evolução de uma sociedade sustentada pela informação e sua influência na economia, nas relações de trabalho e na produção de bens e consumo para uma visão mais integrada, que abarca uma compreensão mais global e analítica sobre a sociedade baseada no conhecimento.

Os reflexos dessas transformações podem ser observados no desenvolvimento da internet, no uso das tecnologias da informação e comunicação (TICs), no invento da inteligência artificial, e nas modificações, por essas causadas, na estrutura social, cultural, econômica, política e institucional, no qual a mídia deixa de comunicar e passa a construir essa nova realidade.

Além disso, essas mutações atingem ainda o sujeito, que agora passa por uma ressignificação do que é ser humano e de sua existência. 0 sujeito e o objeto passam a ser indissociáveis. Ou seja, segundo KUMAR (1997), com a pós modernidade os elementos que classificavam a sociedade já não são encarados em unidades separadas e sim como uma combinação, sendo agora plural (engloba todos os aspectos de uma sociedade), diversa (multisignificados) e difusa (sem direção de atuação).

0 indivíduo é visto como densidade ontológica (tem relação com o significado do ser e da sua existência) à medida que se percebem como parte de algo maior, ou seja, conforme descobre a sua relação com a sociedade/cultura. E isso é de tal naturalidade que o indivíduo passa a não se idealizar separado do coletivo, como corporificação/extensão. Assim, com a transição da sociedade em direção a uma nova pragmática social o indivíduo teve que se ajustar e romper radicalmente com os padrões e práticas anteriores, além de revisar profundamente a produção do conhecimento, seu valor e fonte de crescimento para a sociedade do futuro.

Nesse contexto, o indivíduo que tinha a capacidade de extrair valores, sentidos e significados de suas ações e ser capaz de analisar um elemento de um determinado fenômeno do real e inseri-lo numa visão sistêmica a fim de compreender entre as partes o que constitui o todo; agora, se vê pressionado na tarefa de analisar, sintetizar e interpretar racionalmente todas as formas de ser, estar e de relacionar-se em sociedade; e essas têm-se tornado tarefas difíceis devido à sobrecarga de informações, veracidade das fontes, 0 (não) uso das ferramentas midiáticas em toda sua potencialidade e principalmente a exclusão digital. 
A sociedade pós-industrial ou pós-moderna é uma das denominações usadas para descrever a realidade atual ou "desejada”. Essa não apenas se apresenta como sinônimo de descontinuidade, seja em relação a ideias, paradigmas, ou a evolução do que se conhece de fronteiras políticas, econômicas, filosóficas, culturais e sociais em relação ao pensamento vigente, mas também traz elementos como o multiculturalismo, novas formas de ação social e de grupos sociais, novas relações laborais, raciais, ambientais, ou seja, uma sociedade instável e indeterminada transformada pela modernização.

Para alguns, a cultura pós-moderna seria a manifestação da cultura característica de uma sociedade pós-industrial, ou de uma discussão que envolve a presença de uma sociedade - ou uma "era" -, específica pós-moderna, descrita como um mundo descentralizado, mutável e de particularidades.

Ao analisar a sociedade contemporânea é possível perceber os novos métodos de aquisição, processamento e difusão de informação, o que tem tornado o conhecimento e seu acúmulo sinônimos de eficiência e liberdade acarretando em uma mudança incisiva na organização social.

Essa nova sociedade que tem como principal vetor a informação, visa promover sua democracia, uma vez que difunde informação por toda sociedade, transformando-a na nova moeda do poder, amplamente distribuída, o que contribui para a formação de pessoas mais alertas e cultas (KUMAR, 1997, p.26).

Apesar das pretensões desse novo paradigma da teoria social perdura um sistema de capitalismo globalizado, no qual há graus de exclusão social elevadíssimos, resultantes do controle e abuso de poder por parte dos detentores do capital. Diante deste fato, como estimular uma sociedade mais igualitária, que busca prover o povo de conhecimento e cultura?

Para explicar a problemática que envolve diretamente a aquisição, produção, e difusão de conhecimento na sociedade pós-moderna o estudo tem como objetivo geral investigar se é possível criar uma democracia do saber; e para buscar solucionar essa questão foram traçados os seguintes objetivos específicos: investigar como desenrolou-se a produção do conhecimento humano e científico ao longo da história, identificar as diferenças entre sociedade da informação e do conhecimento e os requisitos para a sua aplicabilidade.

A relevância da temática do ponto de vista social trata de analisar os diversos significados da realidade, baseado nas discussões sobre como vive-se o novo paradigma e os seus reflexos para a realidade social, sobretudo no Brasil. Já para a área acadêmica traz reflexões necessárias e pertinentes sobre as subjetividades na produção do conhecimento e como o modo de ser e estar na pós-modernidade influencia e sofre influência nesta produção. 


\title{
2 DESENVOLVIMENTO
}

\subsection{Constituição do Conhecimento Humano e Científico - Uma revisão histórica}

A gnosiologia entendida como o aporte filosófico que tece questionamentos acerca do conhecimento e preocupa-se, especialmente, com a relação das ideias com a realidade percebida até que ponto consegue-se formar um pensamento capaz, de fato, de explicar a realidade (ao menos aquela à qual se tem acesso)?

A preocupação com a formação de um 'entendimento' sobre as coisas e o próprio ser humano é bastante antiga. Remota ao período pré-histórico, como apresentado por Rushdie:

\begin{abstract}
Até que se desenvolvesse a escrita, inúmeras narrativas foram produzidas e circularam nas sociedades pré-históricas, estruturando-se a partir dos valores e categorias da visão de mundo dos seus principais grupos sociais e contendo informações relativas ao saber adquirido e organizado em milhares de anos de observação dos fenômenos naturais e humanos (RUSHDIE, 1991).
\end{abstract}

A divinização atribuída aos fenômenos naturais consistia na única explicação para a sua existência. Com o fim do nomadismo motivado pelo desenvolvimento de práticas rudimentares de agricultura começam a surgir os primeiros agrupamentos humanos que evoluíram para os clãs e vilarejos. No entanto, é apenas a partir da constituição da civilização greco-romana que a gnosiologia passa a ser enfatizada. Os problemas gnosiológicos, por outro lado, encontram-se muito atrelados a questionamentos voltados para o ser humano.

Notadamente, Aristóteles, Sócrates e Platão contribuem sob maneira para a constituição do conhecimento no ramo da filosofia. Sócrates, o pai da filosofia ocidental - mestre de Platão -, busca 0 entendimento da alma humana, apenas a partir do conhecimento interior (autoconhecimento) é que se consegue chegar à sabedoria e a realização pessoal. Dentro deste raciocínio, Platão contribui a partir de duas abordagens à teoria do conhecimento.

Uma destas abordagens é a ideia de que o conhecimento é a recordação daquilo que já faz parte do cérebro. 0 verdadeiro conhecimento é inato, não depende dos sentidos para ser obtido, é formado por conceitos (ideias previamente adquiridas), e não por informações (ideias que chegam por meio dos sentidos).

A outra abordagem refere-se à Teoria das Formas, que entendia o mundo a partir de seu aspecto visível (voltado para as ideias e as opiniões) e inteligível (voltado para o verdadeiro conhecimento, 
que vai além dos sentidos). Platão denominava de Formas as ideias de "beleza", "verdade" e "justiça”, concebendo-as como existentes e universais independentes do mundo mental das pessoas. A Forma de conhecimento mais necessária (e mais complexa) era o conhecimento do "bem", o saber proporcionado pela filosofia pode levar ao seu conhecimento (ANDERY et al, 2004).

0 verdadeiro conhecimento significa, na visão de Platão, abandonar o mundo dos sentidos e buscar, por meio da razão, descobrir as Formas universais da própria mente. Sua apreensão leva a adquirir o verdadeiro conhecimento e, por fim, à apreensão do Bem (RAEPER, 2001, p.20).

Aristóteles crítica a Teoria das Formas de Platão colocando que em sua concepção 0 conhecimento é, em essência, percepção, este último em conjunto com a experiência dos sentidos são os fundamentos do conhecimento; além do mais não há diferença entre o mundo real e 0 mundo natural, ambos são a mesma coisa. A realidade do mundo encontra-se na "matéria”, na substância da qual o mundo é constituído, e não nas Formas preconizadas por Platão.

A partir do declínio das ideias que moldaram a civilização greco-romana, outras concepções vieram à tona. As ideias apregoadas pelo cristianismo transformaram-se nos fundamentos da sociedade. Dentro deste cenário as ideias de Santo Agostinho serviram de base para o desenvolvimento do cristianismo na Idade Média. Em sua concepção, havia limites para a razão, apoiando-a na fé, que não é cega, mas justificada racionalmente. A razão buscava a compreensão daquilo em que creia a fé.

Agostinho escreveu sobre uma ampla gama de assuntos cristãos. Sua abordagem do passado clássico, sua exposição da Bíblia e o equilíbrio demonstrado entre fé e razão foram importantíssimas realizações e ajudaram a determinar o desenvolvimento do cristianismo nos séculos vindouros (RAEPER, 2001, p.30).

Outro nome de grande relevância foi Tomás de Aquino, cuja ideologia determinava que os conhecimentos são frutos de uma revelação divina, no entanto, admite ser possível obter verdades através da razão e dos sentidos. 0 conhecimento nesta situação assume uma roupagem empírica e racional (ANDERY et al, 2004).

A ascensão do conhecimento científico com grandes pensadores como Leonardo da Vinci, Nicolau Copérnico, Johannes Kepler e Galileu Galilei passam a questionar as verdades da época, colocando em xeque dogmas religiosos a respeito do mundo, este panorama leva a criação de conflitos entre ciência e religião, sendo sua maior expressão a santa inquisição, e o crescimento do ceticismo entre os cientistas.

Em meio a estes conflitos, destacam-se dois nomes: Francis Bacon e René Descartes. Francis Bacon acredita que a razão para estagnação das ciências está na utilização de métodos que impedem 
seu progresso, desta forma, propõe que o avanço da ciência ocorreria a partir de muitas experiências ordenadas, que possibilitariam a retirada de axiomas, e em razão desses realizar novas experiências. Ao método proposto por Bacon dar-se o nome de indução.

0 cientista e filosofo francês Descartes considera que é possível desenvolver uma ciência que fosse aceitável a igreja e tivesse condições de descobrir um fundamento que promovesse uma estrutura para todo o entendimento humano. Apoiando-se na existência de Deus, o filosofo fundamenta a possibilidade do conhecimento verdadeiro.

Descartes enfatiza o racionalismo como fundamento de sua filosofia. 0 racionalismo baseia-se na concepção de que a razão/lógica tem a capacidade de compreender qualquer questionamento, a partir de técnicas que derivam de princípios matemáticos. Em seu livro, Discurso do Método (1637), expõe os quatro princípios de seu método (o método cartesiano), a saber:

Só aceite verdades autoevidentes (como na matemática); decomponha as dificuldades em partes menores a fim de tornar mais fácil sua solução; organize os pensamentos para começar com o mais simples e ir-se aproximando do mais complicado; e assegure-se de ter levado tudo em conta (RAEPER, 2001, p.60).

A filosofia de Descartes tem como fundamento o questionamento, o que pode parecer contraditório, já que a partir da dúvida chega-se a certeza (científica). A primeira premissa ou regra do método cartesiano discorre sobre a clareza e distinção do objeto, deve-se ter certeza da veracidade de uma afirmação. Ao basear-se na ideia de dúvida, expande-a para um questionamento sobre si mesmo, onde a partir de princípios dedutivos, chega ao princípio fundamental de sua filosofia (o racionalismo). Essas afirmações podem ser observadas no trecho do seu livro:

Decidi fazer de conta que todas as coisas armazenadas no meu espírito até aquele momento eram tão ilusórias como meus sonhos. Mas logo percebi: no mesmo instante em que pensava sobre a falsidade do meu conhecimento, era necessário que pelo menos eu, que pensava, fosse alguma coisa. Esta verdade - eu penso, logo existo - era tão firme e certa que as mais extravagantes suposições dos céticos não abalariam. Julguei que podia aceitá-la sem receio, como o princípio fundamental da filosofia que procurava (DESCARTES, parte IV).

A dedução enquanto método de construção lógico é questionado, principalmente, por David Hume. Ora, em sua concepção não é o fato de terem sempre observado cisnes brancos que todos os cisnes são brancos, basta aparecer um cisne de outra cor para colocar em xeque essa afirmação. Desta forma, Hume questiona fortemente o caráter determinista do conhecimento científico, toda dedução é incerta e sujeita a constantes revisões. 0 fundamento principal do método cartesiano (o racionalismo) é questionado, propondo-se uma abordagem empirista. 
Na concepção de Hume, o conhecimento deriva da experiência, sendo essa última, dividida nas impressões e ideias (ou pensamentos), que podem, por fim, ser classificadas em simples ou complexas. Hume conclui que:

Podemos, por conseguinte, dividir todas as percepções do espírito em duas classes ou espécies, que se distinguem por seus diferentes graus de força e de vivacidade. As menos fortes e menos vivas são geralmente denominadas pensamentos ou ideias. A outra espécie não possui um nome em nosso idioma e na maioria dos outros, [...]. Deixe-nos, portanto, usar um pouco de liberdade e denominá-las impressões, empregando esta palavra num sentido de algum modo diferente do usual. Pelo termo impressão entendo, pois, todas as nossas percepções mais vivas, quando ouvimos, vemos, sentimos, amamos, odiamos, desejamos. E as impressões diferenciam-se das ideias, que são percepções menos vivas, das quais temos consciência, quando refletimos sobre quais quer das sensações ou dos movimentos acima mencionados (HUME, seção II).

A complexificação de ideias simples desenrola-se por meio do relacionamento entre elas, ou seja, ao associar várias ideias simples, por meio da atração mútua das ideias devido à sua semelhança, contiguidade e causalidade, tem-se uma complexa. A relação de causa e efeito só ocorre, de fato, se for precedida por uma experiência, não é possível relacionar ideias sem experiências anteriores, por isso, ao ser exposta a algo totalmente novo é impossível para qualquer ser humano (mesmo um gênio) raciocinar encima deste elemento, sendo assim, depende-se da experiência para traçar considerações. Desta forma, a repetição de fatos é denomina por Hume de hábito ou costume. Não é porque percebese constantemente uma força que puxa ao centro da Terra, que essa força vai sempre existir. Logo, 0 fato de a força da gravidade existir no momento não pode ser uma justificativa "racional" para que ela continue existindo.

Outro estudioso que impactou sobremaneira a ciência moderna foi Auguste Comte, o pai da filosofia positivista. Tal filosofia pode ser entendida como uma modelo determinista de observação do conhecimento científico, que é percebido como algo cumulativo e transcultural. A partir das bases de conhecimento presentes nas ciências exatas e biológicas traçam critérios que servem para 0 entendimento de um fenômeno de cunho social. A filosofia de Comte tinha como objetivo a organização da sociedade e modificações nas religiões, em sua visão, a reformulação de instituições só seria possível frente ascensão de uma nova maneira de pensar do ser humano.

A sociedade é regida por leis naturais, invariáveis, independentes da vontade e ação humanas e na vida social reina harmonia. A sociedade pode ser estudada pelos mesmos métodos e processos empregados pelas ciências da natureza. As ciências da sociedade, assim como as da natureza, devem limitar-se à observação e à explicação causal dos fenômenos, de forma objetiva, neutra, livre de julgamentos de valores ou ideologias, descartando previamente todas as pré-noções e pré-conceitos (CHAVES FILHO; CHAVES, 2000, p.73). 
0 pensamento humano (e social) desenvolve-se a partir de três estados, o primeiro deles é 0 teológico, nesse o conhecimento é moldado tendo como alicerce as crenças religiosas, a percepção de que 0 mundo é comandado por divindades. No segundo estado, tem-se o conhecimento metafísico, nessa fase o ser humano procura observar os fenômenos naturais e estabelecer relações possíveis entre eles, sem estabelecer de forma ampla as verdadeiras causas do fato; por fim, a positiva, que busca as causas dos fatos, de uma forma isenta.

A ciência sofre uma nova ruptura, quebrando a tradição da ciência moderna (cumulativo) alçando a categoria de ciência contemporânea (revolucionária, com uma visão mais crítica acerca da produção do conhecimento), tendo como principais nomes: Albert Einstein, Karl Popper e Thomas Kuhn.

Albert Einstein acreditava que a física clássica desenvolvida por Newton não era mais suficiente para responder as leis do campo eletromagnético. Assim, demonstra que ao contrário do que Newton discorria sobre o espaço e o tempo não serem grandezas absolutas, independentes dos fenômenos; como desdobramento acaba por desenvolver a teoria especial da relatividade. Os estudos de Einstein revolucionaram a física, dando um novo prisma inclusive sobre a forma de observar o universo; seus estudos também reverberaram sobre outras áreas de conhecimento.

Karl Popper questiona a lógica positivista principalmente no que se refere a irrefutabilidade do conhecimento científico. Na visão de Popper a ciência deve preocupar-se com a descoberta de soluções para problemas, no entanto, estas soluções não são absolutas; é função das ciências estar sempre refutando-as, pois é apenas a partir da tentativa de desconstrução que o conhecimento de fato evolui.

Thomas Kuhn, pesquisador da Filosofia da Ciência, admitia que para fazer ciência era necessária uma unidade metodológica, paradigma; com a função de estabelecer um padrão de racionalidade, uma visão de mundo. Com a aplicação do paradigma os cientistas já não buscavam descobrir fatos, mas adequar teorias a fatos existentes. A evolução epistemológica ocorreria quando aparecessem anomalias e contratempos que já não poderiam ser explicados pela norma vigente, estando sujeita a uma ruptura e a reformulação de uma nova visão baseadas nas comunidades que as formulam, seus interesses e meio social.

No quadro a seguir, é possível perceber a evolução das correntes filosóficas associadas ao conhecimento e seus principais pensadores e ideias. 
Quadro 1: Algumas correntes filosóficas associadas ao conhecimento

\begin{tabular}{|c|l|c|}
\hline & \multicolumn{1}{|c|}{ Principais ideias } & Pensadores \\
\hline Inatismo & $\begin{array}{l}\text { As ideias são congênitas, já fazem parte das mentes. Para conhecer } \\
\text { basta relembrar. }\end{array}$ & Platão \\
\hline Racionalismo & $\begin{array}{l}\text { Filosofia fundamentada na utilização da lógica (razão) para chegar a } \\
\text { verdade (ao conhecimento rigoroso). }\end{array}$ & Descartes \\
\hline Empirismo & $\begin{array}{l}\text { 0 conhecimento advém das experiências sensoriais. "Nada pode existir } \\
\text { na mente que não tenha passado antes pelos sentidos" (LOCKE apud } \\
\text { RAEPER, 2001). }\end{array}$ & $\begin{array}{c}\text { Aristóteles, John Locke, } \\
\text { Bacon e Hume }\end{array}$ \\
\hline Construtivismo & $\begin{array}{l}\text { A realidade existe, no entanto, é impossível acessá-la da forma } \\
\text { como realmente é, assim, constroem a visão de mundo baseado no } \\
\text { conhecimento que possuem. }\end{array}$ & $\begin{array}{c}\text { Ernst Glasersfeld, Jean } \\
\text { Piaget, e Humberto } \\
\text { Maturana }\end{array}$ \\
\hline Funcionalismo & $\begin{array}{l}\text { As instituições exercem uma função específica na sociedade, seu mal } \\
\text { funcionamento desregula a sociedade }\end{array}$ & $\begin{array}{l}\text { Émile Durkheim e Talcott } \\
\text { Parsons }\end{array}$ \\
\hline Estruturalismo & $\begin{array}{l}\text { A estrutura é uma elaboração teórica que dá sentido aos dados empíricos. } \\
\text { A estrutura é um conjunto de elementos relacionados entre si e com o } \\
\text { todo, interdependentes. }\end{array}$ & $\begin{array}{c}\text { Edward Titchener e } \\
\text { Claude Levi-Strauss }\end{array}$ \\
\hline Pragmatismo & $\begin{array}{l}\text { Valorização da utilidade prática estabelece como critério de verdade } \\
\text { aquilo que se mostra útil }\end{array}$ & $\begin{array}{c}\text { John Dewey e Charles } \\
\text { Peirce }\end{array}$ \\
\hline Positivismo & $\begin{array}{l}\text { 0 conhecimento científico é absoluto e sua evolução transcorre de forma } \\
\text { cumulativa e transcultural. }\end{array}$ & $\begin{array}{c}\text { Auguste Comte e Émile } \\
\text { Durkheim }\end{array}$ \\
\hline
\end{tabular}

Fonte: produzido pelas autoras baseado em Andery et al. (2004) e Raeper (2001).

Na atualidade, o conhecimento científico além de sofrer influência pelas experiencias sensoriais e vivenciais sobre 0 mundo que o cerca também passa a interagir com as TIC's. Ou seja, o conhecimento passa a ser facilmente, observado, acumulado, verificado, e sistematizado e as TIC's permitem uma maior abrangência (raio de alcance de estudo e difusão). Dessa forma, a produção do conhecimento científico tornou-se cada vez mais objetivo e concreto, e o fenômeno da informação adquiriu nova relevância em face da sociedade globalizada. Esse novo olhar revela a importância do conhecimento inter e multidisciplinar na pós-modernidade, exigindo da produção científica a capacidade de adaptar-se à realidade vivenciada dentro da sociedade informacional e do conhecimento.

\subsection{A Formação da Sociedade Informacional e do Conhecimento}

A riqueza de uma sociedade, de acordo com Castells (2009), sempre esteve atrelada à posse de recursos materiais como, propriedades (terras), fontes de energia (petróleo), pedras preciosas, ouro, capital acumulado, etc. No entanto, é na sociedade pós-industrial que a informação e o conhecimento se tornaram ativos (imaterial) de valor imensurável (SILVA, 2016). 
Apesar de exercer um papel substancial na nova economia, a distinção entre os termos, informação e conhecimento, ainda não é nítido. Para Squirra (2006), informação e conhecimento estão associados aos verbos, informar e conhecer, no qual a concepção do que seria informar está atrelada as atividades levantamento, processamento, organização, manipulação e transmissão de dados. Enquanto que o conhecimento consiste no processo de construção realizado pelo sujeito que recebe determinada informação (SILVA, 2016).

A partir do entendimento sobre as diferenças entre os termos, podem-se tecer algumas considerações acerca do que seria a "sociedade da informação" e "sociedade do conhecimento", dentro de uma perspectiva pós-industrial.

De acordo com Burch (2005) a noção da sociedade da informação foi introduzida por Daniel Bell no livro "0 advento da sociedade pós-industrial" (1973). 0 alicerce principal desta sociedade seria 0 conhecimento teórico, onde serviços com foco na produção e/ou transmissão do conhecimento são a sua base econômica. Apesar da forte ênfase dada ao conhecimento, Bell pressupõe que esta sociedade possuiria ideologias bastante superficiais. Com a evolução dos meios de informação e comunicação na década de 90, notadamente aqueles baseados em tecnologia, há uma ressignificação do entendimento da sociedade da informação, que passa a ser vista como uma construção de fundo político-ideológico causado pelo neoliberalismo (econômico) e pela globalização com a intenção de associar benefícios (causados principalmente pela possibilidade de comunicação instantânea estar ao alcance de todos) a realidade de exclusão digital vivida.

Por outro lado, o conceito de sociedade do conhecimento desenvolvido no final da década de 90 pela Organização das Nações Unidas para Educação, Ciência e Cultura (UNESCO) tinha como objetivo desenvolver um conceito que não fosse focado exclusivamente na vertente econômica das TIC's, assim, o conceito de sociedade da informação está relacionada a ideia de inovação tecnológica, tendo como pano de fundo uma questão política-ideológica à medida que a sociedade do conhecimento envolve as transformações pluralistas (de cunho social, político, econômico e cultural) as quais a sociedade vem passando; desta forma, o conceito de "sociedade do conhecimento" pretende dar conta de questões mais complexas voltadas ao desenvolvimento.

Outra maneira de diferenciar os dois tipos de sociedade é tecida por Courrier apud Burch (2005), a expressão "sociedade da informação" dá ênfase no conteúdo do trabalho, ou seja, no processo de captar, processar e comunicar as informações necessárias, enquanto que 'sociedade do conhecimento' destaca os agentes econômicos que devem possuir qualificações superiores para o exercício do seu trabalho. 
A utilização dos termos "sociedade da informação" ou "sociedade do conhecimento" não é consenso entre os estudiosos, Manuel Castells, por exemplo, entende que o termo que melhor designa a realidade da sociedade pós-moderna frente as evoluções das TIC's é "sociedade em rede".

Frequentemente, a sociedade emergente tem sido caracterizada como sociedade de informação ou sociedade do conhecimento. Eu não concordo com essa terminologia. Não porque conhecimento e informação não sejam centrais na nossa sociedade. Mas porque eles sempre 0 foram, em todas as sociedades historicamente conhecidas. 0 que é novo é 0 fato de serem de base microeletrônicas, através de redes tecnológicas que fornecem novas capacidades a uma velha forma de organização social: as redes. [...] A sociedade em rede, em termos simples, é uma estrutura social baseada em redes operadas por tecnologias de comunicação e informação fundamentadas na microeletrônica e em redes digitais de computadores que geram, processam e distribuem informação a partir de conhecimento acumulado nos nós dessas redes (CASTELLS, 2005, p.17).

Castells (2005) fala num processo de informacionalismo que evolui e transforma-se numa sociedade em rede (denominação mais utilizada pelo autor). 0 informacionalismo é apresentado com algumas características principais, a saber:

\begin{abstract}
A informação é sua matéria-prima: a tecnologia se relaciona de forma simbiótica com a informação, elas interagem completando uma a outra; capacidade de penetração dos efeitos das novas tecnologias: os meios tecnológicos exercem grande poder de influência na vida social; lógica de redes: possibilidade de maior interação entre pessoas, processos e organizações; flexibilidade/ adaptabilidade: pode se reconfigurar com frequência; e, convergência de tecnologias específicas para um sistema altamente integrado: o processo de convergência entre a tecnologia leva a um processo de produção de informação onde quem consulta a informação também pode contribuir em seu conteúdo (CASTELLS, 2009, p.69).
\end{abstract}

Interessante notar, que segundo Castells (2009), o que caracteriza a atual revolução tecnológica não é a somente a produção de conhecimentos e informações, mas a aplicação desses para geração de produtos e serviços, formando um ciclo de realimentação entre o processo de inovação e seu uso. Assim, nota-se que a informação é a matéria-prima para gerar conhecimento e novos dispositivos.

Considerar a informação como matéria-prima é inseri-la em um processo de produtivo em que o conhecimento é o produto final. Aqui, o papel da informação, seria o de informar - ato percebido como algo externo ao indivíduo -, ao passo que o conhecimento - enquanto estado -, implicaria num processo de recebimento e (des) construção de algo novo realizado pelo sujeito que recebe determinada informação. Logo, ao versar sobre uma "sociedade informacional" é admitir está como uma etapa precedente da "sociedade do conhecimento" (SILVA, 2016).

Independente da categorização, se, informacional ou do conhecimento, o alicerce dessa nova sociedade os dispositivos com acesso à internet, o que implica na constante evolução de tais tecnologias, pois são elas que permitem a propagação da informação. Sem a evolução desta tecnologia, 
não há o intercâmbio de informações e a constituição dos saberes. No entanto, o processo de evolução e de disponibilização destas tecnologias não decorre de forma simétrica no mundo, com a posição privilegiada de alguns países, a sociedade da informação (termo adotado para o desenvolvimento da pesquisa) mostra suas contradições.

\subsection{Há uma sociedade da informação no Brasil?}

Um dos grandes questionamentos que persegue a pós-modernidade e a sua ideia de sociedade é a de que essa não passa de uma utopia ou, ainda, que seja apenas um rótulo. Isso porque há vários teóricos que descrevem que após a convergência explosiva do computador com as telecomunicações resultou-se numa nova sociedade, tendo a razão centrada no sujeito, descartando o capitalismo que foi o principal vetor da modernidade, mas que é o responsável por distorcer o potencial comunicativo da razão.

As transformações previstas por esses autores vão além do sistema econômico, aliás, de acordo com Toffler (apud KUMAR, 1997, p. 25) essas alterações ocorrerão na esfera técnica, social, de poder, biológica e psicológica. Promovendo não só um novo modo de produção - em que o conhecimento e não o trabalho é a origem do valor - mas a formação de um estilo de vida completo.

Na visão de Masuda (apud KUMAN, 1997, p. 27), defensor desse novo sistema, essa nova sociedade teria que assumir um perfil místico. Formado por homens libertos da automação da necessidade de trabalhar, em que a tecnologia da comunicação tornasse possível dispensar política e governos centralizados, e no seu nível mais alto promovesse uma ligação sinérgica entre homem e natureza. Esta sociedade seria livre de classes, isentas de poder dominante e teria como núcleo comunidades voluntárias. Mais do que uma sociedade, na visão de Masuda encontrar-se a caminho de construir uma civilização inteiramente nova, algo que está "após" ou "além" da modernidade.

Estamos nos dirigindo para o século XXI com o nobre objetivo de construir uma Computopia na terra, em cujo monumento histórico haverá apenas vários chips, um em cada polegada quadrada de uma pequena caixa. Essa caixa, porém, armazenará numerosos registros históricos, incluindo o de como 4 bilhões de cidadãos mundiais que venceram a crise de energia e a explosão demográfica, conseguiram a abolição das armas nucleares e o desarmamento completo, eliminaram o analfabetismo e criaram uma rica simbioses entre Deus e homem, sem a coação do poder ou da lei, mas pela cooperação voluntária dos cidadãos... Assim, a civilização que será construída... Não terá o caráter de uma civilização material caracterizada por edificações imensas, mas será virtualmente uma civilização invisível. Para sermos precisos, ela deveria ser chamada de "civilização da informação" (MASUDA 1985, p. 633-634 apud KUMAR, 1997, p. 27). 
Nesse mesmo raciocínio Daniel Bell (1980 apudKUMAR, 1997, p. 22) expõe que o conhecimento estaria cada vez mais qualitativo e não apenas quantitativo e que seu processamento e disseminação abriria caminho para uma nova era, no qual a informação estará cada vez mais concentrada e será utilizada para satisfazer necessidades mais especializadas e individualizadas. Há uma revolução tecnológica. Nesse estágio o homem não terá mais necessidade de buscar a informação, já que ela pode ser trazida ao lar ou ao escritório por meio dos computadores e da internet. "Uma sociedade centralizada no lar, uma cabana eletrônica" (TOFFLER, 1981: 194-207 apud KUMAR, 1997).

0 principal argumento da crítica é se a sociedade da informação que atua de modo global está de fato modificando radicalmente a vida em sociedade ou apenas reforça ou confirma o sistema vigente, principalmente, no Brasil?

Ao analisar a filosofia proposta pelos autores acima é possível concluir o quão destoante são as suas propostas em comparação a realidade brasileira, o que torna impossível a crença de surgimento de uma nova era, ou uma revolução comparável a Revolução Industrial do século XIX. Ao contrário, do que propuseram a sociedade de informação é um mito criado para servir aos interesses de quem iniciaram e administram a tal "revolução": os setores mais poderosos da sociedade, elites administrativas, militares e as grandes corporações (KUMAR, 1997).

Isso pode ser observado nas características mais notáveis desse modelo de sociedade: a comunicação e a democratização do saber por meio da TIC's. De acordo com os dados da Pesquisa Nacional por Amostra de Domicílios Contínua de 2016 - PNAD, 69,3\% dos lares no Brasil utilizam internet, o equivalente a 48,1 milhões de residências. Essa grande maioria tem acesso a rede por meio do celular constituindo 92,6\% dos domicílios conectados. Nos demais domicílios em que não havia internet, os motivos apresentados na pesquisa foram: "falta de interesse em acessar (34,8\%); preço de acesso era caro (29,6\%); nenhum morador sabia usar (20,7\%); internet não estava disponível na área do domicílio (8,1\%); equipamento eletrônico necessário para acessar era caro (3,5\%)" (IBGE, 2016).

Levando-se em consideração que a rede móvel, principal meio de acesso entre os brasileiros possui limitantes como: velocidade de conexão - espera-se muito tempo para que um site carregue; limite do pacote de dados - o limite do pacote de dados das disponibilizados pelas operadoras muitas vezes não atende as necessidades dos usuários e tem um valor alto; e por último, a falta de cobertura em regiões afastadas - usuários que moram em locais mais apartados, como em cidades rurais, reclamam da falta de serviço de internet. Isso corrobora na descrença do acesso e o uso equitativo das 
TIC's por toda a população, inclusive do aumento da forma de trabalho em perícia e em autonomia, já que a grande massa está a margem desse processo.

Dados da IBGE (2016), demostraram que há uma disparidade no acesso da informação, não só no quesito econômico como também escolar. No Brasil, dos 37,2 milhões de estudantes com 10 anos ou mais, o que representa um total de $81,2 \%$, utilizou a internet. No entanto, quando subdivididos entre as categorias escolas públicas e escolas privadas os resultados são: 75,0\% dos estudantes acessaram a internet na rede pública, em comparação com $97,4 \%$ dos alunos da rede privada.

Nota-se que a problemática da infoexclusão representam a exclusão de oportunidades, seja de conhecimento, de acesso ao trabalho, de estudo. E essas desigualdades presentes entre pobres e ricos adentram na era digital e tendem a aumentar em número e profundidade com a mesma rapidez das novas tecnologias. Ou seja, os cidadãos excluídos digitalmente provavelmente estarão inseridos em mais de um tipo de exclusão social.

A inclusão digital e a democratização do saber por meio dela é um pré-requisito para uma sociedade pós-moderna (KUMAR, 1997). Pois, um indivíduo digitalmente "incluindo" é capaz de fazer uso das novas tecnologias para melhorar sua vida diária, maximizar suas chances de bem-estar pessoal e facilitar as suas tarefas no mundo do trabalho, além de adotar uma postura reflexiva sobre os usos e impactos de tais tecnologias (BOCIC \& GALASSI, 2017).

No entanto, ao estar a margem dessa realidade o indivíduo, a sociedade, ou o país passa a viver no paradigma atual ou anterior?

\section{METODOLOGIA}

0 presente artigo teve como problemática a busca de resposta sobre como estimular uma sociedade mais igualitária, que procura prover o povo de conhecimento e cultura e a possibilidade de criar uma democracia do saber.

Por meio da abordagem qualitativa, foi possível centrar-se na compreensão e explicação da dinâmica de aquisição, produção, e difusão de conhecimento na sociedade pós-moderna. Esta abordagem teórica também permitiu, discutir a ligação entre a paradigma social vigente, suas características e dilemas.

Quanto aos objetivos caracterizou-se como uma pesquisa descritiva, pois almejou delinear os fatos e fenômenos sobre a produção do conhecimento humano e científico ao longo da história, as 
diferenças entre sociedade da informação e/o do conhecimento e os requisitos para a sua aplicabilidade na realidade brasileira.

Com relação aos procedimentos foi utilizada a pesquisa bibliográfica feita a partir do levantamento de referências teóricas, escritas e eletrônicas, como livros, páginas de web e artigos científicos. A busca dos documentos científicos e a formação do banco de dados foi feita a partir da base de dados do Directory of Open Access Journals (DOAJ), Dialnet e SCIELO SciELO (scientific electronic library online) através da estrutura de busca, Constituição do Conhecimento Humano e Científico, Sociedade Informacional e Sociedade do Conhecimento, e pós modernidade, com suas respectivas traduções para o idioma inglês, Constitution of Human and Scientific Knowledge, Information Society and Knowledge Society, postmodernity, com filtros nos anos de 2016 a 2018. A partir do processo de pesquisa foram encontrados ao todo dois artigos nas bases de dados citadas, os quais não tinham total aderência a essa investigação. Sendo assim, a pesquisa baseou-se, quase que completamente, por livros.

\section{CONSIDERAÇÕES FINAIS}

Diante dos fatos apresentados nos capítulos anteriores é possível inferir que o novo paradigma aliado as TIC's não podem ter aplicabilidade na realidade brasileira, por ser impossível o cumprimento de suas prerrogativas.

Chega-se à conclusão também sobre a sua total inaplicabilidade em outras realidades sociais. Visto que, de acordo com o filósofo francês, Lévy (1999 p.230), “Cada novo sistema de comunicação fabrica seus excluídos", essa afirmação remete a ideia de que mesmo com acesso as mídias, as tecnologias e a informação jamais se alcançará a cidadania plena a todos, uma vez que em qualquer sociedade haverá o "não acesso" agravando ainda mais o quadro de desigualdade social.

Contudo, apesar do apartheid digital, que um terço da população brasileira faz parte, a sociedade não regride. Pois, a maioria dos indivíduos, que são digitalmente incluídos, contribuem para o aumento das indústrias criativas, sabem do papel do conhecimento e suas aplicações, faz uso da mão de obra (diferente do que se conhece). E, consequentemente, na medida em que há o crescimento da inovação em produtos e serviços, há também dos postos de trabalho e credencialíssimo - isto é, a exigência de qualificações mais altas para os mesmos empregos -, criando uma impressão errônea de profissionais mais cultos disfarçando a exclusão de grupos inteiros de profissionais, em especial da área de serviços que não tem acesso a qualificação (KUMAR, 1997; BOCIC; GALASSI, 2017). 
É perceptível também a expansão e criação de novos tipos de trabalho na indústria da informação relativos a computadores, componentes eletrônicos, telecomunicações, software que exigem altos níveis de competência técnica e conhecimento teórico, o que corresponde a educação e treinamento de qualidade, sendo esses últimos a cerne para solucionar o abismo que divide a sociedade contemporânea quanto a democratizando do saber.

Por fim, como afirma Kumar (1997, p.71), em seu capítulo sobre a Ideologia e a Sociedade da Informação, "A nova tecnologia está sendo aplicada em uma estrutura política e econômica que confirma e reforça padrões existentes ao invés de gerar outros". Aqui o desconstrucionismo foi tão implacavelmente subversivo que acabou por subverter a si mesmo. Ou seja, desigualdades sociais existentes são mantidas e ampliadas. Conhecimento e informação que figuravam entre os recursos mais públicos agora são mercadorias expropriadas para venda e lucro. E o projeto de uma nova sociedade terminou como as anteriores, "por e para uns poucos: as ricas e poderosas classes, nações e regiões do mundo".

Recomenda-se que trabalhos futuros abordem projetos e práticas que possam auxiliar na democratização do saber e que visem subverter o panorama vigente dos excluídos digitais.

\section{REFERÊNCIAS}

ANDERY, Maria Amália et al. Para compreender a ciência. 13 ed. Rio de Janeiro: Garamond; São Paulo: EDUC, 2004.

BOCIC, Paola Espina; GALASSI, Jorge Gibert. El capital informacional como condición de la inclusión digital: un análisis . Psicol. Conoc. Soc., Montevideo, nov, v. 7, n. 2, p. 25-44, 2017 . Recuperado de $<$ http://www.scielo.edu.uy/scielo.php?script=sci_arttext\&pid=S1688-70262017000200025\&Ing=es\&n $\mathrm{rm}=\mathrm{is} 0>$

BORDIEU, Pierre. Os usos sociais da ciência: Por uma sociologia clínica do campo científico. São Paulo: Editora UNESP, 2002.

BRITO, Ana Paula dos Santos; LUNA, Edilvan Moraes. A Educação Superior e Os Limites Absolutos do Capital: precarização do trabalhador qualificado e contradição da educação superior em tempos de crise estrutural do capital. In: PAIVA, Maria Jeanne Gonzaga., LIMA, Maria Messias Ferreira., PINHEIRO, Valéria Feitosa., \& et al (organizadores). Capitalismo, trabalho e política social. São Paulo: Edgard Blücher Ltda, 2017. Recuperado de http://pdf.blucher.com.br.s3-sa-east-1.amazonaws. com/openaccess/9788580391879/07.pdf Acesso em

BURCH, Sally. Sociedade da Informação/ Sociedade do Conhecimento. In: AMBROSI, Alain., PEUGEOT, Valérie., \& PIMIENTA, Daniel. Desafios de palavras: enfoques multiculturais sobre as sociedades da informação. Caen-France: C \& F Éditions, 2005. 
CASTELLS, Manuel. A sociedade em rede - volume I (A era da informação: economia, sociedade e cultura). 12.ed. São Paulo: Paz e terra, 2009.

CASTELLS, Manuel. A sociedade em rede: do conhecimento à política. In: CASTELLS, Manuel., \& CARDOSO, Gustavo. (org.). A sociedade em rede: do conhecimento à ação política. Belém: Imprensa Nacional/ Casa da cultura, 2005. Recuperado de http://www.egov.ufsc.br:8080/portal/sites/default/ files/anexos/a_sociedade_em_rede_-_do_conhecimento_a_acao_politica.pdf. Acesso em:

CHAVES FILHO, Manoel Moacir; CHAVES, Suzana Maria. A ciência positivista: o mundo ordenado. In: Revista de Iniciação Científica CESUMAR. Ag-Dez, Vol. 02 n. 02, pp. 69-75 69, 2002.

DESCARTES, René. 0 discurso do método, 2013. Recuperado de http://lelivros.love/book/downloaddiscurso-do-metodo-rene-descartes-em-epub-mobi-e-pdf-2/.

HUME, David. Investigação acerca do entendimento humano. Recuperado de http://www. livrosgratis.com.br/arquivos_livros/cv000027.pdf

IBGE, Instituto Brasileiro de Geografia e estatística. Pesquisa nacional por amostra de domicílios contínua - pnad contínua, 2016. Recuperado de ftp://ftp.ibge.gov.br/Trabalho_e_Rendimento/ Pesquisa_Nacional_por_Amostra_de_Domicilios_continua/Anual/Acesso_Internet_Televisao_e_ Posse_Telefone_Movel_2016/Analise_dos_Resultados.pdf

KUMAR, Krishan. Da sociedade pós-industrial à pós-moderna: novas teorias sobre o mundo contemporâneo. Rio de Janeiro: Jorge Zahar Ed, 1997.

LÉVY, Pierre. Cibercultura. São Paulo: Editora 34, 1999.

RAEPER, William; SMITH, Linda. Introdução ao estudo das ideias: religião e filosofia no passado e no presente. 2. ed. São Paulo: Loyola, 2001.

RUSHDIE, Salmon. Haroun e o mar de histórias. São Paulo: Paulicéia, 1991.

SILVA, H. K. C. S. A aprendizagem significativa nos programas de treinamento corporativo: um estudo no banco do brasil e na caixa econômica federal. 2016. 159 f. (Programa de Pós-Graduação em Administração). PROPAD, Universidade Federal de Pernambuco - UFPE, Recife - PE, 2016.

SQUIRRA, Sebastião Carlos de Morais. Sociedade do conhecimento. Revista Comunicação \& Sociedade, v. 27, n. 45, 2006. 